\title{
Cerebral localization of the center for reading and writing music
}

\author{
Mitsuru Kawamura, ${ }^{\mathrm{CA}}$ Akira Midorikawa' and Machiko Kezuka \\ Department of Neurology, Showa University School of Medicine, I-5-8 Hatanodai, Shinagawa-ku, Tokyo I42-8666; 'Department \\ of Psychology, Chuo University Graduate School, Tokyo; ${ }^{2}$ Department of Rehabilitation, Tokyo Metropolitan Kiyose Hospital, \\ Tokyo, Japan \\ ${ }^{\mathrm{CA}}$ Corresponding Author
}

Received 25 July 2000; accepted 2 August 2000

The mechanisms that underly the ability to read and write music remain largely unclear compared to those involved in reading and writing language. We had the extremely rare opportunity to study the cerebral localization of the center for reading and writing music in the case of a professional trombonist. During rehearsal immediately before a concert, he suffered a hemorrhage that was localized to the left angular gyrus, the area that has long been known as the center for the ability to read and write. Detailed tests revealed that he showed symptoms of alexia with agraphia for both musical scores and language. NeuroReport II:3299-3303 $\quad$ (C) 2000 Lippincott Williams \& Wilkins.

Key words: Angular gyrus; Musical agraphia; Musical alexia

\section{INTRODUCTION}

Towards the end of the 19th century, Dejerine [1] performed clinical and anatomical studies on patients with alexia and agraphia, and was the first to demonstrate that the center for reading and writing was located in the left angular gyrus. One reason for the importance attached to Dejerine's finding [1] is that a large number of patients with alexia and agraphia resulting from lesions of the left angular gyrus have been reported since the report of Geschwind [2] in 1965. Another reason is the recent study by Horwitz et al. [3] on brain activation, which promoted interest in clarifying the intracerebral mechanisms underlying the ability to read and write.

Like speech, the intracerebral mechanisms underlying music have also long interested researchers. Many books targeted at general audiences suggest that the left side of the brain is involved in speech and the right side of the brain is involved in musical ability. However, the mechanisms underlying musical ability are less clear than those involved in speech. This is primarily because individual differences in musical ability far exceed those in speech ability. Individual differences in the ability to read and write musical scores are even greater than differences in singing ability, as only people who have received special training can accurately read and write musical scores.

We had the extremely rare opportunity to study the cerebral localization of the center for reading and writing musical scores in the case of a professional trombonist, trained to read and write music. During a rehearsal immediately before a concert, he suffered a hemorrhage that was localized to the left angular gyrus, which has long been known as the center for the ability to read and write.

\section{CASE REPORT}

Patient K.M., a right-handed orchestral trombonist, was 57 years old. On February 3, 1997, during a rehearsal immediately before a concert, the subject was suddenly unable to read the part scores of Tchaikovsky's Symphony No. 5. He confused the alto and tenor clefs, and could not understand how the position of one note related to that of others or the meanings of sharp and flat signs. On February 12, 1997, we were given the opportunity to be involved in his medical treatment. The subject was fully conscious. No disorders of the cranial nerves, motor, or sensory systems were observed. No aphasia, apraxia, or agnosia was observed; however, the loss of the ability to read and write sentences and musical scores was observed. No abnormality in either the expression or perception of music was observed.

K.M. began learning to play the trombone when he was in junior high school. He was then admitted into a high school affiliated with a university specializing in music, where he earnestly began learning the trombone, piano, and solfége, with basic training in reading and writing musical scores. Soon after graduation from university, he joined a symphony orchestra as a professional musician, and played the trombone as a member of a worldrenowned orchestra in Tokyo for over 30 years.

A ring-enhancing lesion was observed in the horizontal and coronal sections of T1-weighted images of an MRI obtained on February 20, 1997 (Fig. 1). The only lesion observed was in the left angular gyrus.

Table 1 shows the results of general neuropsychological tests. The subject's level of intelligence was evaluated 2 weeks after the hemorrhage using the Japanese version of 


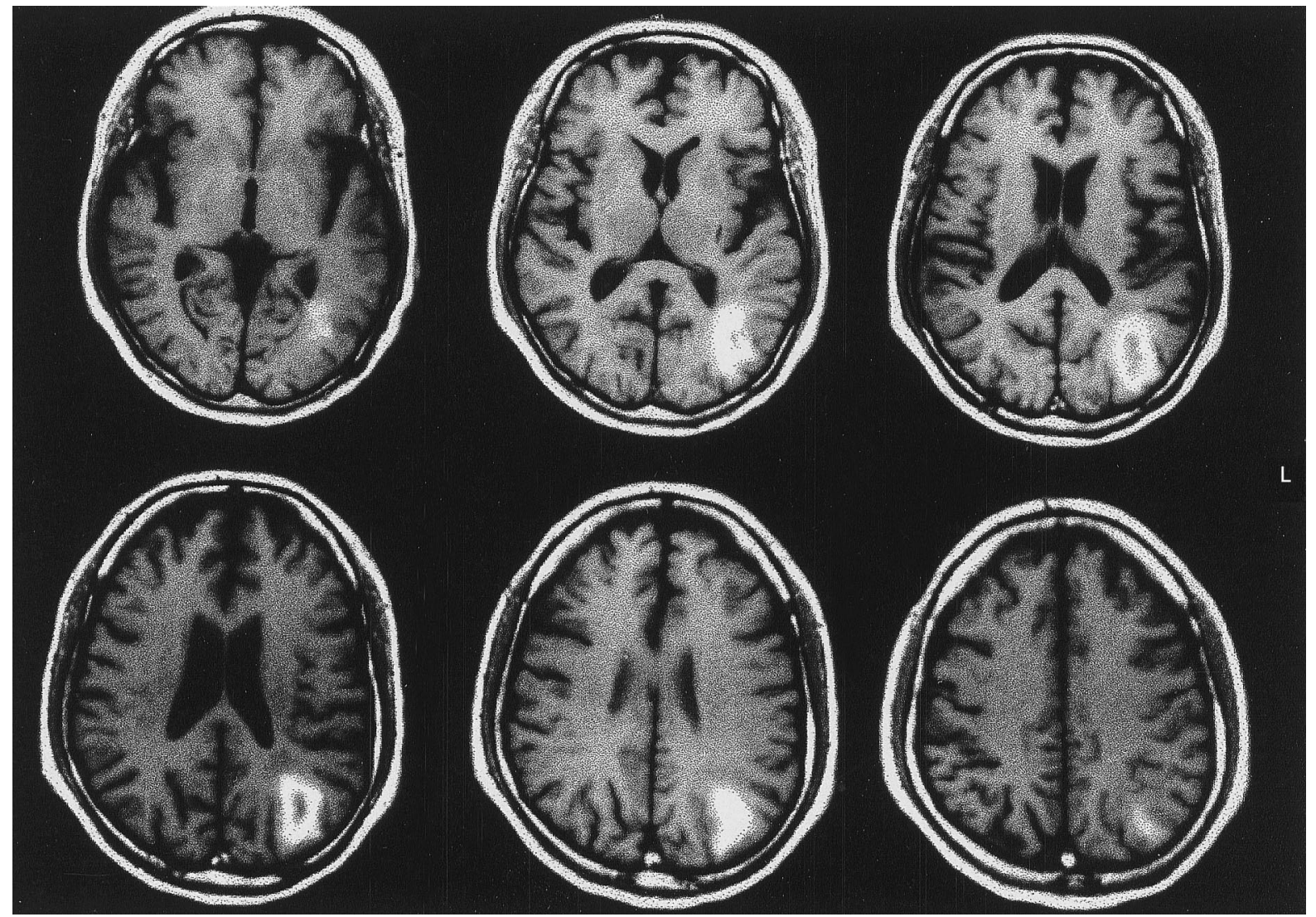

Fig. I. TI-weighted horizontal MRI image. Elliptical ring-enhancing lesions localized to the left angular cortex and subcortical white matter are observed.

Table I. Results of the general neuropsychological tests.

\begin{tabular}{ll}
\hline WAIS-R & \\
Full scale IQ & 108 \\
Verbal IQ & 109 \\
Performance IQ & 104 \\
Western Aphasia Battery (WAB) & \\
Fluency & $20 / 20$ \\
Auditory comprehension & $8.95 / 10$ \\
Repetition & $10 / 10$ \\
Naming & $9.5 / 10$ \\
Reading & $10 / 10$ \\
Writing & $9.85 / 10$ \\
AQ & 97 \\
Token Test & $158 / 165$ \\
I00 Words Naming Test & $99 / 100$ \\
Kohs Block Design Test-IQ & 129 \\
Benton Visual Retention Test & \\
Correct & 8 \\
Error & 3 \\
Raven Colored Progressive Matrices & $32 / 36$ \\
\hline
\end{tabular}

These tests were evaluated 2 weeks after the hemorrhage. No abnormalities were observed. His reading and writing disorder could not be clarified by a standardized language test (WAB).
Wechsler Adult Intelligence Scale-Revised (WAIS-R). His full-scale intelligent quotient (IQ), verbal IQ, and performance IQ were 108, 109, and 104, respectively; all normal values. The Japanese version of the Western Aphasia Battery (WAB) performed 2 weeks after the hemorrhage revealed an AQ of 97, a nearly normal level. However, the scores for auditory comprehension of language, naming, and writing were slightly abnormal, at 8.95, 9.5 and 9.85, respectively. Meanwhile, the scores for spontaneous speech, repetition, and reading were perfect. The Token Test revealed 158 correct responses out of 165 , which is normal. No abnormalities were observed in the auditory comprehension of language. A 100-word naming test produced 99 correct responses out of 100, which is normal. In other words, scarcely any abnormality was observed in the patient's understanding of characters or words, indicating that his reading and writing disorder could not be clarified by a standardized language test. Kohs Block Design Test revealed an IQ of 129. In the Benton Visual Retention Test, the numbers of correct and incorrect answers were eight and three, respectively, both normal scores. No abnormalities in visuospatial perception or constructional function were observed. The Raven Colored Progressive Matrices (RCPM) tests revealed a normal score 
of 32 and no abnormality in intellectual function. The ability to copy and draw objects and pictures, such as flowers, a house with trees, and a cube were normal, and showed no signs of left hemineglect. No left-right agnosia was observed. The subject could correctly name commonly used goods, showing no sign of visual agnosia or optic aphasia. Furthermore, he could correctly perceive the meaning of map symbols and road signs and explain their meanings verbally.

\section{METHODS AND RESULTS}

Music: We tested the subject's ability to read and write various musical scores four times, 2, 6, 15, and 52 weeks after the onset of the disorder.

The subject was instructed to perform seven tasks involving reading single notes, rhythm, determining key, and reading melody, musical symbols, part scores, and full scores. The results of these reading tests are shown on the left of Fig. 2. Four different staff notations (violin, bass, tenor, and alto clefs) containing 32 quarter notes were used to evaluate his ability to read single notes. The subject was instructed to name each note, and all his responses were correct in all four tests conducted. To evaluate his ability to read rhythm, a musical score was prepared that showed a rhythm in eight measures equivalent to 20 notes. The subject was then instructed to tap the rhythm of the musical score on a desk with his knuckles. He correctly read all the rhythms in all four tests conducted. In order to evaluate his ability to determine the key, he was shown four scales and was instructed to determine the key of each scale. All his responses were correct in all four tests conducted. In order to evaluate his ability to read the melody, we read two musical pieces, each consisting of eight measures, taken from a solfége text used in the entrance examination of a high school specializing in music. Then we replaced the two songs with the alto and tenor clefs used for a trombone musical score. The subject was instructed to write the name of the sound under each note. Two weeks after the onset of the disorder, he gave 14 correct responses out of 16 , i.e., $88 \%$. Six weeks after the onset of the disorder, he gave 15 correct responses out of 16 , i.e., $94 \%$. Fifteen weeks after onset of the disorder, he gave 16 correct responses out of 16 , i.e., $100 \%$. One year after the onset of the disorder, he gave 15 correct responses out of 16 , i.e., $94 \%$. In order to evaluate his ability to read musical symbols, he was presented with 12 symbols and was instructed to identify them. All his responses were correct, except in the first test, conducted 2 weeks after the onset of the disorder (10 correct responses out of $12(83 \%)$.

To evaluate his ability to read part scores, we crossed out the titles to the trombone parts for five symphonies that the subject had played several times before the onset of the disorder, and presented them to him. The symphonies were Tchaikovsky's Symphony No. 5, Elgar's Pomp and Circumstance, Dvorak's Symphony No. 9, Liszt's Poem Symphonique No. 3 Les Preludes, and Beethoven's Symphony No. 5. The subject was instructed to identify each symphony. He gave four correct responses out of five, i.e., $80 \%$, in the first test, conducted 2 weeks after the onset of the disorder. However, all his responses were correct in the three subsequent tests. To evaluate his ability to read full scores, we crossed out the titles of three symphony

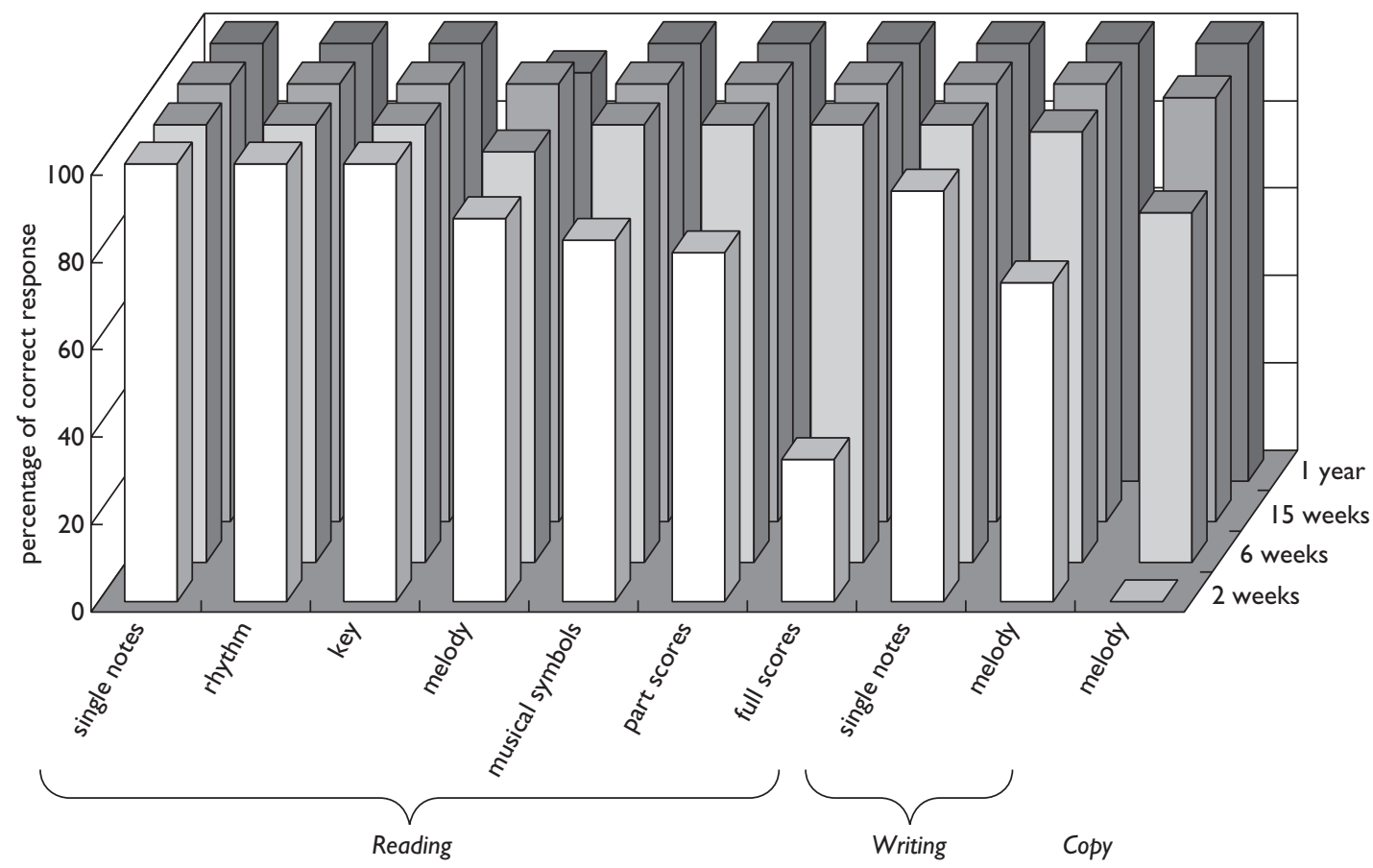

Fig. 2. Results of tests of the ability to read and write music. The tests were conducted at 2, 6, 15, and 52 weeks after the onset of the disorder (the copying test was not performed at 2 weeks). In reading musical scores, a greater degree of impairment was observed in reading part scores or full scores than for single notes. In writing musical scores, the trombonist's ability to write single notes or trombone melodies that he knew well was impaired. Impairment was also observed in his ability to copy. All of these deficits recovered gradually. 
scores that he had played several times previously and instructed him to identify the titles of the pieces. The pieces were Bruchner's Symphony No. 4, Debussy's Prelude to L'après-midi d'un faune, and Berlioz's March Hongroise. Two weeks after the onset of the disorder he gave one correct answer out of three, i.e., 33\%. However, all his responses were correct in the three subsequent tests.

We had the subject perform two tests, writing single notes and writing songs from memory, to evaluate his writing ability. The results of the two tests are shown in Fig. 2. To evaluate his ability to write single notes, we read him 12 notes in German and instructed him to write them in four staff notations (violin, alto, tenor, and bass clefs). Two weeks after the onset of the disorder, he gave 45 correct answers out of 48, i.e., 94\%. However, all his responses were correct in the three subsequent tests. Next, to evaluate the subject's ability to write songs from memory, we instructed him to write the notes of a musical piece that he said he remembered and hummed correctly, in staff notation. The piece was the famous trombone chorus of the fourth movement in Symphony No. 1 by Brahms. Two weeks after the onset of the disorder, he wrote 11 out of 15 measures correctly, i.e., 73\% (Fig. 3), and all his responses were correct in the tests conducted 15 weeks and one year after the onset of the disorder. As shown in Fig. 3, almost all the writing errors were attributed to a wrong musical interval, and not to an incorrect rhythm.

We prepared a melody consisting of four measures, including sixteenth notes, and instructed the subject to copy it. This test was performed three times, beginning 6 weeks after the onset of the disorder. The results are shown on the right-hand side of Fig. 2. Errors were observed in the test conducted 6 weeks after the onset of the disorder and in the second test conducted 15 weeks after the onset of the disorder, whereas few errors were observed in the remaining test. All these errors were attributed to incorrect musical interval.

Language: Disorders of reading and writing characters and words are rarely observed in the WAB. We tested the subject's ability to read and write sentences three times: 2, 15 , and 52 weeks after the onset of the disorder.

In order to evaluate the subject's reading ability, we instructed him to silently read the leading article in a newspaper, which contained 600 Japanese characters, having first ensured that he had not previously read the article. He was instructed to read it as usual, not to read
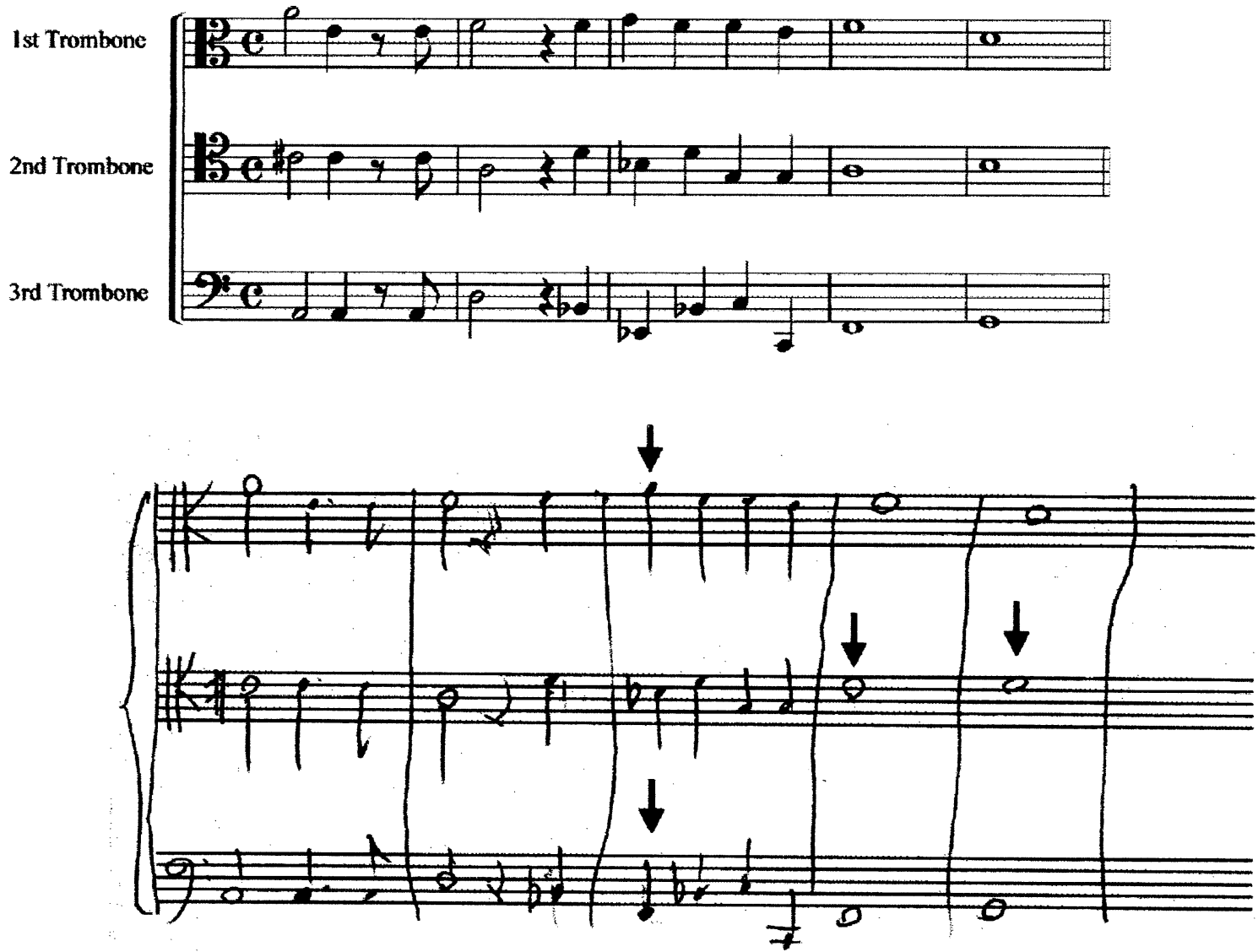

Fig. 3. Results of tests of the ability to write musical scores that the subject knew well. The subject was instructed to write from memory the notes of the trombone chorus of the fourth movement in Symphony No. I by Brahms. He knew the tune well, and was able to hum it. The correct score is shown above, and the score written by the subject 2 weeks after the hemorrhage is shown below. Arrows indicate errors, all of which are attributable to incorrect musical intervals. 
aloud, and say when he had finished reading. We then asked him questions to evaluate his comprehension of the article. We also compared the length of time that it took him to read it with that taken by the examiner. He correctly comprehended the contents of the newspaper articles 2 and 15 weeks after the onset of the disorder. In both tests, however, it took him longer to finish reading than the examiner. Two weeks after the onset of the disorder, it took him $72 \mathrm{~s}$ while the examiner took $25 \mathrm{~s}$, and at 15 weeks it took him $75 \mathrm{~s}$ vs $28 \mathrm{~s}$ for the examiner. In the test conducted 1 year after the onset of the disorder, the subject took $68 \mathrm{~s}$, whereas the examiner took $58 \mathrm{~s}$; the difference between the two was obviously reduced. Therefore, we concluded that his reading ability had recovered to a normal level.

To evaluate his writing ability, an examiner read aloud a newspaper article that the subject had not previously read and instructed him to write it down. The subject was told to write what was read out, using kanji if necessary. We studied the results of this test, separating the correct responses in kanji and kana. In the first test, 2 weeks after the onset of the disorder, the numbers of correct transcriptions when writing the dictated newspaper article were 16 correct kanji out of 23, and 21 correct kana out of 22. These scores gradually improved to a normal level: 15 weeks after the onset of the disorder he wrote 19 out of 23 kanji and 22 out of 22 kana correctly, and one year after the onset of the disorder he wrote 22 out of 23 kanji and 23 out of 23 kana correctly. The errors were due to incorrect spelling or to difficulty in recalling the correct kanji or kana.

\section{DISCUSSION}

Since the autopsy report on Dejerine's patient with alexia and agraphia in 1891 [1] the left angular gyrus has been considered to be an important center for the ability to read and write. Friedman et al. [4] confirmed the significance of the left angular gyrus, and this is currently treated in textbooks and dictionaries [5] as an established fact. Based on Dejerine's initial autopsy case [1], Geschwind's report [2], and numerous reports of patients with alexia without agraphia, it is considered that the route from the visual area of the occipital lobe to the left angular gyrus is particularly significant for the intracerebral mechanism of visual language.
Our subject, a practising musician with a long career as a professional trombonist and advanced education in music, developed a localized lesion in the left angular gyrus. In addition to alexia with agraphia of language, alexia with agraphia of musical scores was also observed. A localized injury in the left angular gyrus of a professional musician has not been reported previously, making this the first reported case.

In 1992, Sergent et al. [6] measured the brain activity of pianists while they played the piano and looked at a musical score, using PET. Measurement by PET revealed that when pianists read a musical score, but did not play it, the left parieto-occipital lobe, which includes the left angular gyrus, as well as the visual field of the occipital lobes bilaterally, was activated. Sergent et al. [6,7] also reported that the brain regions activated in professional musicians when music was being processed were similar to those activated during the processing of language, unlike in nonprofessionals. The results of the study by Sergent et al. [6] are consistent with our case.

It is reasonable to conclude that the angular gyrus in the left side of the brain plays a significant role in the ability of professional musicians to read and write music, just as it does in individual's ability to read and write language.

\section{CONCLUSION}

The angular gyrus in the left side of the brain plays a significant role in the ability of professional musicians to read and write music, just as it does in individual's ability to read and write language.

\section{REFERENCES}

1. Dejerine J. Mem Soc Biol 3, 197-201 (1891).

2. Geschwind N. Brain 88, 237-294, 585-644 (1965).

3. Horwits B, Rumsey JM and Donohue BC. Proc Natl Acad Sci 95, 8939-8944 (1998).

4. Friedman R, Ween JE and Albert M. Alexia. In: Heilman KM and Valenstein E, eds. Clinical Neuropsychology, 3rd edn. Oxford: Oxford University Press; 1993, pp. 37-62.

5. Beaumont J, Kenealy PM and Rogers MJC, eds. The Blackwell Dictionary of Neuropsychology, 1st edn. Cambridge: Blackwell Publishers; 1996, pp. 38-43.

6. Sergent J, Zuck E, Terriah S et al. Science 257, 106-109 (1992).

7. Sergent J. Hum Brain Mapp 1, 20-38 (1993).

\footnotetext{
Acknowledgements: The authors would like to thank Drs Keiji Tanaka (RIKEN Brain Science Institute) and Yoshiaki Iwamura (Toho University) for their support and insightful suggestions. This work was supported by Japanese Ministry of Education, Science and Culture Grants-in-Aids for Scientific Research (08279105).
} 